\title{
Teaching Medical Students about Communicating with Patients with Major Mental Illness
}

\author{
Lisa I. lezzoni, MD, MSc, ${ }^{7}$ Radhika A. Ramanan, MD, MPH, ${ }^{2}$ Stacey Lee, MSW, LICSW ${ }^{3}$ \\ 'Division of General Medicine and Primary Care, Charles A. Dana Research Institute, Harvard-Thorndike Laboratory, Beth Israel \\ Deaconess Medical Center, Boston, MA, USA; ${ }^{2}$ Center for Health Education, Long Beach Memorial Medical Center, University of \\ California, Irvine, CA, USA; ${ }^{3}$ Department of Social Work, Beth Israel Deaconess Medical Center, Boston, MA, USA.
}

\begin{abstract}
Persons with major mental illness often have chronic diseases and poor physical health. Therefore, all practicing physicians should learn about communicating effectively with these patients. Few efforts to teach medical students communication skills have specifically targeted patients with major mental illness. Indeed, most of the limited literature on this topic is decades old, predating significant scientific advances in cognitive neuroscience and psychiatric therapeutics and changes in social policies regarding major mental illness. To gather preliminary insight into training needs, we interviewed 13 final-year students from 2 Boston medical schools. Students' observations coalesced around 4 themes: fears and anxieties about interacting with persons with major mental illness; residents "protecting" students from patients with major mental illness; lack of clinical maturity; and barriers to learning during psychiatry rotations. Educational researchers must explore ways to better prepare young physicians to communicate effectively with patients with major mental illness.
\end{abstract}

KEY WORDS: mental illness; communication skills; medical education. DOI: $10.1111 / \mathrm{j} .1525-1497.2006 .00521 . \mathrm{x}$

J GEN INTERN MED 2006; 21:1112-1115.

$\mathrm{P}$ ersons with major mental illness often have worse physical health and more chronic conditions, such as diabetes, respiratory illnesses, and cardiovascular disease, than other persons. ${ }^{1-3}$ They also have higher rates of smoking, obesity, physical inactivity, substance abuse, and other risky health behaviors. ${ }^{4-11}$ Despite this, numerous barriers impede persons with major mental illness from obtaining medical care beyond psychiatric services. ${ }^{12,13}$ Persons themselves may not seek services because of impaired recognition of health needs, fears of coercive treatments, and uncertainty about where to go. ${ }^{14,15}$ "Carve out" payment policies can force persons to receive psychiatric care outside the general health care system. ${ }^{16-18}$ Persons with major mental illness lack health insurance more often than others, making them less likely to receive mental health services. ${ }^{19,20}$ Persons with major mental illness report difficulties finding empathic primary care clinicians and worry that physicians misunderstand psychiatric disability and neglect their somatic complaints. ${ }^{21}$

Most physicians receive little training in interacting with patients with major mental illness ${ }^{22}$ and can feel uncomfortable or ineffective communicating with them, even about physical complaints. ${ }^{23,24}$ Although not used in the Diagnostic and Statistical Manual of Mental Disorders (DSM-IV ${ }^{\mathrm{TM}}$ ), ${ }^{25}$ the phrase "major mental illness" refers shorthand to such serious

Address correspondence and requests for reprints to Dr. Iezzoni: Division of General Medicine and Primary Care, Department of Medicine, Beth Israel Deaconess Medical Center RO-137, 330 Brookline Avenue, Boston, MA 02215 (e-mail: liezzoni@bidmc.harvard.edu).

1112 diagnoses as schizophrenia, paranoid states, and other nonorganic psychoses, major mood disorders (e.g., major depressive and bipolar disorders), and certain anxiety disorders (e.g., panic attack, obsessive-compulsive disorder, agoraphobia), among others. All conditions significantly impede communication, such as the "disorganized speech, grossly disorganized or catatonic behavior" and "prominent hallucinations" of certain psychoses. ${ }^{25}$ Untrained clinicians newly confronting persons with these disorders may feel uncertain about how to conduct even basic communication. Educators increasingly teach medical students about communicating with patients, ${ }^{26}$ including persons with disabilities, ${ }^{27}$ but few have addressed communication skills specifically involving major mental illness. Teaching students specific communication skills for persons with major mental illness will improve their future abilities to provide patient-centered care to this potentially vulnerable population.

\section{Little Evidence to Guide Medical Student Teaching about Communication}

Teaching related to major mental illness, including communication, offers challenges different from many other clinical fields. Even basic topics, such as diagnostic nomenclature, appear "different." Whereas most specialties rely upon the International Classification of Diseases to code clinical conditions, mental health professionals use DSM-IV. ${ }^{25}$ As leading medical educators suggest, however, "any physician ... must be able to diagnose, treat, manage, and refer patients with psychiatric disorders." 28 By definition, this requires effective communication skills.

Relatively few publications address teaching medical students about psychiatry, let alone communicating with persons with major mental illness. Most existing literature reaches back 2 or more decades. A 1967 study found that medical students rated surgery and psychiatry clerkships poorly, primarily because students served passively as observers rather than therapists. ${ }^{29}$ Two 1980 surveys confirmed several previous studies, with medical students rating psychiatry as unscientific, imprecise, and of a lower status than other medical specialties ${ }^{30}$ or as "easy" or "very easy" compared with other clerkships. $^{31}$

Since those early studies, tremendous advances have occurred in neurobiology, molecular biology, genetics, neuro-

Manuscript received December 9, 2005

Initial editorial decision February 20, 2006

Final acceptance April 7, 2006 
imaging, pharmacology, and cognitive neuroscience, alongside projected future shortages of psychiatrists. ${ }^{32}$ Rubin and Zorumski ${ }^{32}$ urge increasing psychiatric education during both preclinical and clinical undergraduate medical training. Two older studies question prevailing assumptions, finding that students do learn from interacting directly from psychiatric patients $^{33}$ and do not discomfit patients. ${ }^{34}$ Otherwise, little guidance is available to suggest training strategies. Methods to teach medical students about interacting with persons with major mental illness urgently require a fresh look.

\section{What Students Told Us}

To gather insights into training needs, we turned directly to students. Using similar methods as described elsewhere, ${ }^{35}$ in February 2002, we conducted 2 focus group interviews with 13 total students nearing graduation and asked how they had been taught about communicating with persons with major mental illness.

We approached Boston, Harvard, and Tufts University Medical Schools; 2 schools allowed us to recruit their students. We invited all students who responded to our solicitation e-mail to participate. Institutional review boards at Beth Israel Deaconess Medical Center and Harvard Medical School approved this study; students gave written informed consent. Our moderator's guide, reviewed with 2 senior psychiatric social workers within our general medical practice, addressed students' views of living with major mental illness, their education about communicating with patients with these conditions, and suggestions for communication skills training in this context. The lead author moderated the focus groups.

A professional transcription service produced verbatim transcripts. Using Nvivo (Melbourne, Australia), qualitative text analysis software, we sorted the texts by coding categories representing common topics identified during preliminary reviews of the transcripts. We used "grounded theory" concepts to identify themes. ${ }^{36}$ After completing preliminary analyses, 2 mental health clinicians not involved previously in the study independently read the transcripts to assess the trustworthiness of our findings.

Ten participants were women; 6 self-identified as white, 4 as Asian, and 3 as Hispanic. These individuals do not represent medical students nationwide. We treat their comments as suggestive of areas for research into developing effective training programs. Among their observations, 4 common themes stood out. (All names below are pseudonyms.)

\section{Addressing Students' Fears}

Teaching cannot happen until students feel "safe." Typically, educators think of safety in purely intellectual terms (e.g., feeling safe to express ignorance, discomfort). In the context of major mental illness, however, more basic physical safety concerns may dominate. "The image is of someone harassing you on the New York City subway," said James, "or the movie One Flew Over the Cuckoo's Nest." While acknowledging potential fallacies of stereotyped, stigmatizing depictions, interviewees nonetheless admitted that they felt scared or anxious when confronting strangers with presumed major mental illness in public, concerned about their personal safety and perceived threats to "private space." "I don't know what their motivations are," observed Martha. "I don't know what their boundaries are."

Students recognized that context affects their emotional reactions to individuals with major mental illness. They described clinical contexts as "safer environments," albeit from their own perceptions rather than how patients might feel. Nonetheless, some expressed difficulty understanding how their own fears or anxieties might influence their care of patients. Questions arose especially about patients with additional stigmatizing factors, notably substance abuse. During emergency room rotations, students from 1 medical school frequently saw homeless persons with dual diagnoses of mental illness and alcohol or drug abuse. Aspects of their presentations (e.g., poor hygiene, strong odors, violent behaviors) evoked complex responses. As Jill admitted:

I hate to say it, but I do not want to deal with that patient. The odor itself is so repulsive. [Staff] tell me, "You need to have some people clean the patient up before you can even talk to him." ... It definitely hinders communication when a patient comes in smelling very bad, cursing, and being very violent. But I'm so embarrassed [to feel this way.] He's still a person—he's still a patient.

A first lesson for educators is anticipating and acknowledging students' fears and other complex emotions. Educators might encourage students to consider the implications of their perceptions for patient care, as well as strategies to handle legitimate concerns (e.g., fears relating to safety, personal hygiene).

\section{Residents Limit Students' Exposure to Mental Illness}

Critical learning in clinical rotations comes from students' observations of residents. During their nonpsychiatry clerkships, students reported that residents often explicitly "protected" them from having to "deal with" persons with mental illness, who residents themselves viewed as burdensome. Residents effectively hid major mental illness and its treatment from students. As Amy recounted, "They'll specifically say, 'If there are any psych issues, just don't take this patient-we'll deal with it. It's our job, but there's no reason you should have to do it.",

The students thought nonpsychiatry residents themselves strive to avoid mental health issues; after identifying psychiatric illness, residents immediately "call a psych consult." Students perceived that nonpsychiatry physicians "look down" on psychiatrists in the "medical hierarchy." Some students witnessed physicians not assessing physical symptoms as thoroughly in patients with histories of psychiatric disease as they would with other patients. Several students blamed the extra time involved for busy residents' reluctance to treat patients with mental illness.

Whether our findings-that residents "protect" medical students from mental illness-generalize to other hospitals requires further study. Nonetheless, this possibility raises several broader issues, including helping students to set priorities when time is limited and understanding responsibilities for overseeing patient care. The implications of marginalizing mental health issues for overall health care quality also deserve discussion.

\section{Lack of Clinical and Scientific Maturity}

Although focus group participants were nearing medical school graduation, they described psychiatric conditions 
using "lay language," lacking clinical specificity or scientific nomenclature (e.g., language from DSM-IV) with which they discuss other medical conditions. They often prefaced their comments by saying that they had not directly experienced mental illness, so had difficulty fully appreciating it (although, of course, they had likely not experienced most somatic illnesses that they encountered). Samantha described 1 patient from her psychiatry rotation:

She said she was seeing dinosaurs and aliens everywhere and was being told that she was Jesus Christ and had to kill herself or the world would end. I understand that was so real to her. I don't think I could possibly imagine how terrifying that must be ... Or a patient who is depressed or suicidal-it seems almost beyond my comprehension to feel so bad about yourself or about your life that you don't want to live it any more.

Interviewees described their perceptions of major mental illness in empathetic terms, speaking of loss, isolation, and struggle, as well as socioeconomic deprivation. Martha felt that "the illness, more than a lot of other illnesses, takes over your life and in some ways defines your life." But interviewees did not mention treatment possibilities or improved patient outcomes. Educators must therefore focus on basic fund of knowledge about mental illness, nomenclature to provide precise, clinically credible descriptions of psychiatric conditions, and therapeutic expectations.

\section{Barriers to Learning During Psychiatry Rotations}

Students consistently said that optimal learning comes from interactions with actual patients: "The best was one-on-one interviewing with a psych resident standing in the background giving feedback directly afterwards," said James. Students also valued feedback from patients. During her psychiatry rotation, Erica interviewed several patients and then got "feedback from the patient about how they felt about talking with me. That was more useful than anything else."

During psychiatry rotations, direct patient-student interactions were more limited than in other clerkships. During psychiatry rotations, the students' position outside the therapeutic team sometimes prevented them from face-to-face contacts with patients. "Some people had an antagonistic feeling toward having medical students present," Martha observed, "like we were interfering with the group dynamic."

Some students said they had inadequate opportunities to build their communication skills. They felt that limiting their direct access to psychiatric patients was sometimes legitimate but that situations can become extreme. During 1 teaching session, 12 students interviewed a single patient when other psychiatric patients who had initially volunteered dropped out. Although students generally dismissed watching videotaped interviews as inferior to direct patient contact in learning interviewing skills, they held somewhat different views in psychiatry. As Carolyn said:

We can learn how to hold a stethoscope or listen to the lungs of our friends, and then go recreate that with patients. But it's much more difficult to teach the psych exam in that way. For that reason, seeing an interaction before you go in cold to the patient on your own is very important. If videotape is the only way to do it, that's fine.

Despite complaints about limited direct patient exposure during their psychiatry rotations, most students said they had learned from their experiences. "One of the most important things I learned was about overcoming my own fears about mental illness," observed Sharon. "That was something that I found very difficult initially, but that could be overcome by experience."

\section{Recommendations}

Improving cultural competence of trainees has gained interest among medical educators, anticipating that this might reduce disparities in health care. Leading medical educators have added "the culture of disability" to this educational focus, ${ }^{27}$ albeit without specifically including persons with psychiatric disabilities. More research and experimentation is needed to develop new models for training medical students about communicating with patients with major mental illness. As Rubin and Zorumski ${ }^{32}$ suggest, these are exciting times for learning about mental health disorders. Some fears expressed by the students suggest that today's training approach may not effectively convey burgeoning scientific insight into major mental illness, as well as the current emphasis on positive outcomes and recovery for persons with these disorders. Medical school curricula typically separate courses to teach effective communication skills from those that teach medical knowledge and other clinical skills. ${ }^{37}$ Our interviews suggest the value of exploring approaches that combine communication skills training with more scientific teaching and clinical skills training about major mental illness. For example, providing greater scientific knowledge about the neurobiological bases for some psychiatric disorders alongside communication training could give students added insight and confidence in interacting with these patients. Such an integrated approach remains to be tested.

Students can learn much about psychiatry on nonpsychiatry rotations, but the focus group participants described explicitly negative messages that they received during clinical experiences, especially devaluing and diverting patients with mental health needs from the medical mainstream into psychiatric referral networks. On 1 level, that may give patients appropriate care. But it removes important opportunities for students to learn and treat the entire patient, not just the mental illness. We recommend that medical educators consider addressing these issues by educating learners at all levelsmedical students, residents, and faculty.

Our medical student interviewees described discomfort or disinterest primarily among residents in other disciplines for addressing patients' psychiatric concerns. They said little about attitudes among attending physicians. However, residents' behaviors likely parallel their teachers' interests and behaviors. Educating attending physicians could possibly instill the skills to teach their trainees about communicating with persons with major mental illness. Some programs have taught communication skills to faculty, ${ }^{38-40}$ but we are unaware of training initiatives oriented specifically toward patients with major mental illness.

One interesting teaching initiative involved integrating communication training into a required family medicine clerkship. ${ }^{41}$ The program included both a student curriculum and faculty development. One novel component was "on site consultations" from specially trained behavioral scientists, observing preceptors, providing feedback, and paralleling the teaching process used with students. A similar program about communicating with patients with major mental illness could help facilitate the transfer of skills from attendings to trainees. 
All physicians involved in direct patient care need the language, communication skills, and confidence to communicate effectively with persons with major mental illness. Our interviews suggest that the challenge of developing superb communication skills with these patients extends beyond training medical students. Larger cultural contexts in which faculty operate powerfully shape the values and attitudes of learners. Medical educators should consider both faculty and student needs and behaviors in designing communication skills improvement programs.

This research received generous support from the Katz Family Foundation. We thank Evette Weil Ferguson, MD, then a research assistant, for her support with logistics and text coding. We are grateful to Stephen O'Neill, MSW, for reviewing the moderator's guide and Gillian K. Wies, MD, for reviewing the focus group transcripts and discussing our findings.

\section{REFERENCES}

1. Himelhoch S, Lehman A, Kreyenbuhl J, Daumit G, Brown C, Dixon L. Prevalence of chronic obstructive pulmonary disease among those with serious mental illness. Am J Psychiatry. 2004;161:2317-9.

2. Sokal J, Messias E, Dickerson FB, et al. Comorbidity of medical illnesses among adults with serious mental illness who are receiving community psychiatric services. J Nerv Ment Dis. 2004;192:421-7.

3. Casey DE. Metabolic issues and cardiovascular disease in patients with psychiatric disorders. Am J Med. 2005; 118(suppl 2):15S-22S.

4. Devlin MJ, Yanovski SZ, Wilson GT. Obesity: what mental health professionals need to know. Am J Psychiatry. 2000;157:854-66.

5. Ziedonis D, Williams JM, Smelson D. Serious mental illness and tobacco addiction: a model program to address this common but neglected issue. Am J Med Sci. 2003;326:223-30.

6. Grant BF, Hasin DS, Chou SP, Stinson FS, Dawson DA. Nicotine dependence and psychiatric disorders in the United States: results from the national epidemiologic survey on alcohol and related conditions. Arch Gen Psychiatry. 2004;61:1107-15.

7. McElroy SL, Kotwal R, Malhotra S, et al. Are mood disorders and obesity related? A review for the mental health professional. J Clin Psychiatry. 2004;65:634-51.

8. Susce MT, Villanueva N, Diaz FJ, de Leon J. Obesity and associated complications in patients with severe mental illnesses: a cross-sectional survey. J Clin Psychiatry. 2005;66:167-73.

9. Drake RE, Wallach MA, Alverson HS, Mueser KT. Psychosocial aspects of substance abuse by clients with severe mental illness. J Nerv Ment Dis. 2002;190:100-6.

10. Xie H, McHugo GJ, Fox MB, Drake RE. Substance abuse relapse in a ten-year prospective follow-up of clients with mental and substance use disorders. Psychiatr Serv. 2005;56:1282-7.

11. Drake RE, Wallach MA, McGovern MP. Future directions in preventing relapse to substance abuse among clients with severe mental illnesses. Psychiatr Serv. 2005;56:1297-302.

12. Druss BG, Rosenheck RA. Mental disorders and access to medical care in the United States. Am J Psychiatry. 1998;155:1775-7.

13. Dickerson FB, McNary SW, Brown CH, et al. Somatic healthcare utilization among adults with serious mental illness who are receiving community psychiatric services. Med Care. 2003;41:560-70.

14. Jeste DV, Unutzer J. Improving the delivery of care to the seriously mentally ill. Med Care. 2001;39:907-9.

15. Hahm HC, Segal SP. Failure to seek health care among the mentally ill. Am J Orthopsychiatry. 2005;75:54-62.
16. Ray WA, Daugherty JR, Meador KG. Effect of a mental health "carveout" program on the continuity of antipsychotic therapy. N Engl J Med. 2003;348: 1885-94

17. Iglehart JK. The mental health maze and the call for transformation. $\mathrm{N}$ Engl J Med. 2004;350:507-14.

18. Mechanic D, Bilder S. Treatment of people with mental illness: a decade-long perspective. Health Aff. 2004;23:84-95.

19. McAlpine DD, Mechanic D. Utilization of specialty mental health care among persons with severe mental illness: the roles of demographics, need, insurance, and risk. Health Services Res. 2000;35:277-92.

20. Edlund MJ, Wang PS, Berglund PA, et al. Dropping out of mental health treatment: patterns and predictors among epidemiological survey respondents in the United States and Ontario. Am J Psychiatry. 2002;159:845-51.

21. O'Day BL, Killeen MB, Sutton J, Iezzoni LI. Primary care experiences of people with psychiatric disabilities: barriers to care and potential solutions. Psych Rehabil J. 2005;28:339-45.

22. Lieberman JA, Lieberman JA III. Compliance issues in primary care. J Clin Psychiatry. 1996;57(suppl 7):76-82.

23. Jackson JL, Kroenke K. Difficult patient encounters in the ambulatory clinic: clinical predictors and outcomes. Arch Intern Med. 1999;159: 1069-75.

24. Hahn SR. Physical symptoms and physician-experienced difficulty in the physician-patient relationship. Ann Intern Med. 2001;134:897-904.

25. American Psychiatric Association. Diagnostic and Statistical Manual of Mental Disorders, Fourth Edition (DSM-IV ${ }^{\mathrm{TM}}$ ). Washington, DC: American Psychiatric Association; 1994.

26. Makoul G. Essential elements of communication in medical encounters: the Kalamazoo Consensus Statement. Acad Med. 2001;76:390-3.

27. Eddey GE, Robey KL. Considering the culture of disability in cultural competence education. Acad Med. 2005;80:706-12.

28. Klamen DL, Sandlow L. Restructuring the role of psychiatry in medical education. Acad Med. 1996;71:1030-1.

29. Castelnuovo-Tedesco P. How much psychiatry are medical students really learning? Arch Gen Psychiatry. 1967;16:668-75.

30. Yager J, Lamotte K, Nielsen A III, Eaton JS Jr. Medical students' evaluation of psychiatry: a cross-country comparison. Am J Psychiatry. 1982; 139:1003-9.

31. Bashook PG, Weissman SH. Senior medical students' perceptions of the psychiatric clerkship. Am J Psychiatry. 1982;139:1614-6.

32. Rubin EH, Zorumski CF. Psychiatric education in an era of rapidly occurring scientific advances. Acad Med. 2003;78:351-4.

33. Oldham JM, Sacks MH, Nininger JE, Blank K, Kaplan RD. Medical students' learning as primary therapist or as participant/observers in a psychiatric clerkship. Am J Psychiatry. 1983;140:1615-8.

34. Santulli RB. Patients and students: what do they think of each other? Acad Med. 1993;68(suppl 10):S40-S2.

35. Iezzoni LI, Ramanan R, Drews RE. Teaching medical students about communicating with patients who have sensory or physical disabilities. Disability Studies Quart. 2005;25. Available at: www.dsq-sds.org.

36. Glaser BG, Strauss AL. Discovery of Grounded Theory: Strategies for Qualitative Research. Chicago: Aldine de Gruyter; 1967.

37. Duffy FD, Gordon GH, Whelan G, et al. Assessing competence in communication and interpersonal skills: the Kalamazoo II Report. Acad Med. 2004;79:495-507.

38. The Josiah Macy Jr. Foundation. The Macy Initiatives in Health Communication. Information available at: www.josiahmacyfoundation.org/ current.html\#Macy.

39. Communication Skills Program. Dalhousie University. Information available at: medcomm.medicine.dal.ca.

40. Lang F, Everett K, McGowen R, Bennard B. Faculty development in communication skills instruction: insights from a longitudinal program with "real-time" feedback. Acad Med. 2000;75:1222-8.

41. Egnew TR, Mauksch LB, Greer T, Farber SJ. Integrating communication training into a required family medicine clerkship. Acad Med. 2004;79:737-43. 